\title{
IMPLEMENTASI ALGORITMA K-NEAREST NEIGHBOR UNTUK IDENTIFIKASI KUALITAS AIR (STUDI KASUS: PDAM KOTA SURAKARTA)
}

\author{
Rio Adi Arnomo"); Wawan Laksito Yuly Saptomo ${ }^{2)}$; Paulus Harsadi ${ }^{3)}$ \\ 1) 2) 3) Program Studi Teknik Informatika, STMIK Sinar Nusantara \\ 1)akunrio09@gmail.com; ${ }^{2)}$ wlaksito@sinus.ac.id; ${ }^{3)}$ paulusharsadi@sinus.ac.id
}

\begin{abstract}
Water quality in urban areas in Surakarta has decreased nowadays. The increase of industrial development, its poor sewage treatment, and some other factors cause this urban problem. The result of water quality monitoring system with K-Nearest Neighbor algorithm on this research certainly will help the laborers' duty of PDAM (Local Government Owned Water Utilities) in analyzing water quality. For the consideration of majority output in this method, the system works by taking the nearest distance to the assigned number of $K$. The training data for this research was taken in March 2016 form the report of water monitoring result in PDAM'S laboratory of Surakarta. The identification result is divided into eligible (MS) and ineligible (TMS). The testing data result is applied in algorithm performance testing with confusion matrix having accuracy level $82,5 \%$.
\end{abstract}

Keywords : Water Quality, K-Nearest Neighbor, Confusion Matrix

\section{PENDAHULUAN}

Air merupakan kebutuhan penting bagi masyarakat perkotaan pada khususnya. Kebutuhan air bersih tiap tahun mengalami peningkatan sedangkan ketersediaan air bersih semakin terbatas, dikarenakan sempitnya daerah resapan, banyaknya pembangunan yang tidak memperhatikan keseimbangan alam, eksploitasi sumber air baku yang tidak terjaga kelestarian sumber air. Salah satu masalah pokok yang dihadapi adalah kurang tersedianya sumber air bersih.

Berdasarkan Peraturan Menteri

Kesehatan Republik Indonesia Nomor 492/MENKES/PER/IV/2010 tentang Persyaratan Kualitas Air Minum terdapat pengertian mengenai Air Minum yaitu air yang melalui proses pengolahan atau tanpa proses pengolahan yang memenuhi syarat kesehatan dan dapat langsung diminum. Kualitas air yang layak konsumsi bagi masyarakat, perlu adanya identifikasi dini terhadap produk air dari sumber air baku serta faktor-faktor yang mempengaruhinya. Tujuan penelitian ini untuk melakukan early warning untuk identifikasi kualitas air dengan mengklasifikasikan data menggunakan metode algoritma $K$-Nearest Neighbor (K-NN). Kontribusi implementasi algoritma K-NN untuk lingkungan sendiri sudah cukup banyak antara lain untuk peramalan temperatur air[1], peramalan banjir [2] bahkan dalam perubahan iklim [3]. Algoritma ini termasuk kelompok instancebased learning. Algoritma ini juga merupakan salah satu teknik lazy learning. KNN dilakukan dengan mencari kelompok $\mathrm{k}$ objek dalam data training yang paling dekat (mirip) dengan objek pada data baru atau data testing. Algoritma K-Nearest Neighbor adalah sebuah metode untuk melakukan klasifikasi terhadap objek berdasarkan data pembelajaran yang jaraknya paling dekat dengan objek tersebut[4]. K-NN sendiri merupakan teknik yang sudah umum digunakan dalam berbagai bidang penelitian salah satunya text categorization [5][6][7] bahkan dalam object recognition [8].

\section{TINJAUAN PUSTAKA}

\subsection{Sistem Penunjang Keputusan}

Sistem Pendukung Keputusan mempunyai komponen-komponen adalah sebagai berikut [9]:

a. Data Management

Termasuk database yang mengandung data yang relevan untuk berbagai situasi dan diatur oleh software.

b. Model Management

Melibatkan model finansial, statistikal, management science, atau berbagai model kualitatif lainya, sehingga dapat memberikan ke sistem suatu kemampuan analitis dan manajemen software yang dibutuhkan.

c. Communication / Interface User dapat berkomunikasi dan memberikan perintah pada DSS melalui subsistem ini. 
d. Knowledge Management

Subsistem optional ini dapat mendukung subsistem lain atau bertindak sebagai komponen yang berdiri sendiri.

\subsection{Kualitas Air}

Air merupakan salah satu sumber daya alam yang memiliki fungsi sangat penting bagi kehidupan dan perikehidupan manusia, serta untuk memajukan kesejahteraan umum, sehingga merupakan modal dasar dan faktor utama pembangunan. Air yang dikonsumsi oleh masyarakat harus memiliki standar air bersih yang telah ditetapkan oleh KEMENKES no.492/Menkes/Per/IV/2010 dalam peraturan yang diterbitkan pada tahun 2010.

Tabel 1. Kadar yang diperbolehkan

\begin{tabular}{|l|l|l|l|}
\hline No & Jenis Parameter & Satuan & \multicolumn{1}{|c|}{$\begin{array}{c}\text { Kadar yang } \\
\text { ditentukan }\end{array}$} \\
\hline 1 & Parameter fisik & & \\
\hline & a) Bau & & Tak berbau \\
\hline & b) Rasa & & Tak berrasa \\
\hline & c) Warna & ${ }^{\circ} \mathrm{C}$ & \\
\hline & d) Suhu & $\mathrm{TCU}$ & Suhu udara $\pm 3^{\circ}$ \\
\hline & e) Kekeruhan & $\mathrm{NTU}$ & 5 \\
\hline 2 & Parameter kimia & & \\
\hline & a) Sisa Clor & $\mathrm{mg} / \mathrm{l}$ & $0,2-0,5$ \\
\hline & b) Besi & $\mathrm{mg} / \mathrm{l}$ & 0,3 \\
\hline & c) Mangan & $\mathrm{mg} / \mathrm{l}$ & 0,4 \\
\hline & d) Kesadahan & $\mathrm{mg} / \mathrm{l}$ & 500 \\
\hline & e) Nitrit & $\mathrm{mg} / \mathrm{l}$ & 3 \\
\hline & f) Amonium & $\mathrm{mg} / \mathrm{l}$ & 1,5 \\
\hline & g) Kalium & $\mathrm{mg} / \mathrm{l}$ & \\
\hline & permanganat & & \\
\hline h) Ph & & $6,5-8,5$ \\
\hline i) Klorida & $\mathrm{mg} / \mathrm{l}$ & 250 \\
\hline j) sulfat & $\mathrm{mg} / \mathrm{l}$ & 250 \\
\hline
\end{tabular}

\section{METODE PENELITIAN}

\subsection{Data Primer}

Data yang dibutuhkan dalam penelitian ini adalah hasil wawancara dan observasi mengenai uji kualitas air di laboratorium PDAM Kota Surakarta.

\subsection{Data Sekunder}

Data sekunder umumnya berupa bukti, catatan atau laporan historis yang tersusun dalam arsip. Data yang dibutuhkan dalam penelitian ini adalah laporan uji lab kualitas air bulan Maret dan April 2016 di PDAM kota Surakarta sebagai data training sebanyak 111 data.

\subsection{Metode K-Nearest Neighbor}

Algoritma K-NN sangatlah sederhana, bekerja berdasarkan jarak terpendek dari query instance ke training sample untuk menentukan K-NN-nya. Training sample diproyeksikan ke ruang berdimensi banyak dimana tiap dimensi merepresentasikan fitur dari data. Ruang ini dibagi menjadi bagianbagian berdasarkan klasifikasi training sample. Sebuah titik pada ruang ini ditandai kelas $c$ jika kelas $c$ merupakan klasifikasi yang paling banyak ditemui pada $k$ buah tetangga terdekat dari titik tersebut [10]. Untuk mendefinisikan jarak antara dua titik yaitu titik pada data training $(x)$ dan titik pada data testing (y) maka digunakan rumus Euclidean, seperti yang ditunjukkan pada persamaan

$\mathrm{D}(\mathrm{x}, \mathrm{y})=\sqrt{\sum_{k-1}^{n}\left(x_{k}-y_{k}\right)^{2}}$

Dengan $D$ adalah jarak antara titik pada data training $x$ dan titik data testing yang akan diklasifikasi, dimana $\mathrm{x}=\mathrm{x} 1, \mathrm{x} 2, \ldots, \mathrm{xi}$ dan $\mathrm{y} 1, \mathrm{y} 2, \ldots, \mathrm{yi}$ dan I mempresentasikan nilai atribut serta $\mathrm{n}$ merupakan dimensi atribut. Langkah-langkah untuk menghitung metode Algoritma K-nearest Neighbor [4]:

a. Menentukan Parameter K (Jumlah tetangga paling dekat).

b. Menghitung kuadrat jarak Euclid (query instance) masing-masing objek terhadap data sampel yang diberikan

c. Kemudian mengurutkan objek-objek tersebut ke dalam kelompok yang mempunyai jarak Euclid terkecil.

d. Mengumpulkan kategori Y (Klasifikasi Nearest Neighbor).

e. Dengan menggunakan kategori Nearest Neighbor yang paling mayoritas maka dapat diprediksi nilai query instance yang telah dihitung.

\subsection{Pengujian Confusion matrix}

Metode ini menggunakan tabel matriks seperti padaTabel 1 jika data set hanya terdiri dari dua kelas, kelas yang satu dianggap sebagai positif dan yang lainnya negatif [11].

Tabel 2 Model Confusion Matrix

\begin{tabular}{|l|l|l|}
\hline \multirow{2}{*}{$\begin{array}{l}\text { Klasifikasi } \\
\text { yang benar }\end{array}$} & \multicolumn{2}{|l|}{ Diklasifikasikan sebagai } \\
\cline { 2 - 3 }+ & + & - \\
\hline- & true positives & false negatives \\
\hline & false positives & true negatives \\
\hline
\end{tabular}

True positives adalah jumlah record positif yang diklasifikasikan sebagai positif, false positives adalah jumlah record negatif yang diklasifikasikan sebagai positif, false negatives adalah jumlah record positif yang diklasifikasikan sebagai negatif, true negatives adalah jumlah record negatif yang diklasifikasikan sebagai negative, kemudian 
masukkan data uji. Setelah data uji dimasukkan ke dalam confusion matrix, hitung nilai-nilai yang telah dimasukkan tersebut untuk dihitung jumlah sensitivity (recall) specificity, precision dan accuracy. Sensitivity digunakan untuk membandingkan jumlah TP terhadap jumlah record yang positif sedangkan specificity adalah perbandingan jumlah TN terhadap jumlah record yang negatif. Untuk menghitung digunakan persamaan di bawah ini [12]:

sensitivity $=\frac{T P}{P}$

specificity $=\frac{T N}{N}$

precision $=\frac{T P}{T P+F P}$

accuracy $=$ sensitivity $\frac{P}{(P+N)}+$ specificity $\frac{N}{(P+N)}(5)$

Keterangan:

$\begin{array}{ll}\text { TP } & =\text { jumlah true positives } \\ \text { TN } & =\text { jumlah true negatives } \\ \mathrm{P} & =\text { jumlah record positif } \\ \mathrm{N} & =\text { jumlah tupel negatif } \\ \mathrm{FP} & =\text { jumlah false positives }\end{array}$

IV. HASIL DAN PEMBAHASAN

4.1. Pembahasan

Penelitian ini menggunakan 111 record hasil analisa kualitas air baik yang Memenuhi Syarat ataupun Tidak Memenuhi Syarat diambil dari laporan analisa kualitas air PDAM Surakarta. Berikut pada Tabel 3 menjelaskan variabel respon yang digunakan dalam penelitian ini.

Tabel 3. Variabel respon

\begin{tabular}{|l|l|}
\hline ASPEK & VARIABEL \\
\hline \multirow{5}{*}{$\begin{array}{l}\text { Parameter } \\
\text { fisik }\end{array}$} & $\begin{array}{l}\text { Pemeriksaan Sample Air } \\
\text { (1 }=\text { MS (Memenuhi Syarat), } 2=\end{array}$ \\
& TMS (Tidak Memenuhi Syarat) \\
\cline { 2 - 2 } & $\mathrm{X}_{1}:$ Bau \\
\cline { 2 - 2 } & $\mathrm{X}_{2}:$ Rasa \\
\cline { 2 - 2 } & $\mathrm{X}_{3}:$ Suhu \\
\cline { 2 - 2 } & $\mathrm{X}_{4}:$ Warna \\
\cline { 2 - 2 } & $\mathrm{X}_{5}:$ Kekeruhan \\
\hline Karameter & $\mathrm{X}_{6}:$ Sisa Clor \\
\cline { 2 - 2 } & $\mathrm{X}_{7}:$ pH \\
\cline { 2 - 2 } & $\mathrm{X}_{8}:$ Kesadahan \\
\cline { 2 - 3 } & $\mathrm{X}_{9}:$ Besi \\
\cline { 2 - 2 } & $\mathrm{X}_{10}:$ Mangan \\
\cline { 2 - 2 } & $\mathrm{X}_{11}:$ Amonium \\
\cline { 2 - 2 } & $\mathrm{X}_{12}:$ Nitrit \\
\hline
\end{tabular}

\begin{tabular}{|l|l|}
\hline ASPEK & VARIABEL \\
\hline \multirow{4}{*}{} & $\mathrm{X}_{13}:$ kalium permanganat \\
\cline { 2 - 2 } & $\mathrm{X}_{14}:$ Klorida \\
\cline { 2 - 2 } & $\mathrm{X}_{15}:$ Sulfat \\
\hline
\end{tabular}

Data yang nilainya bersifat nominal akan diubah menjadi data numerik. Pada Tabel 3 data yang masih bersifat nominal adalah bau dan rasa. Tabel 4 merupakan perubahan data nominal ke numerik.

Tabel 4. Nilai atribut bau dan rasa

\begin{tabular}{|l|c|}
\hline Atribut & Nilai \\
\hline Berbau & 1 \\
\hline Tak berbau & 2 \\
\hline Berrasa & 1 \\
\hline Tak berrasa & 2 \\
\hline
\end{tabular}

Perhitungan dilakukan dengan 15 variabel data yaitu data fisik dan numerik. Data testing akan dihitung jarak terdekat dengan masing-masing data training. Misalkan sebuah data sampel kualitas air yang berlokasi di Toko Djoyo apakah memenuhi syarat atau tidak memenuhi syarat maka akan dihitung jarak terdekat dengan data training yang sudah ada.

Contoh perhitungan dengan algoritma K-Nearest Neighbor:

a. Menentukan parameter $\mathrm{K}$, misal $\mathrm{K}=7$

b. Menghitung kuadrat jarak euclidean (euclidean distance) masing-masing obyek terhadap data sampel yang diberikan

$\mathrm{D}(\mathrm{x}, \mathrm{y})=\sqrt{\sum_{k-1}^{n}\left(x_{k}-y_{k}\right)^{2}}$

$d(1,1)=$

$=\left((0)^{2}+(0)^{2}+(4)^{2}+(0)^{2}+(-0,04)^{2}+(0)^{2}+\right.$

$(0,5)^{2}+(12)^{2}+(0,07)^{2}+(-0,79)^{2}+(0,13)^{2}+(0)^{2}$

$\left.+(0,01)^{2}+(26)^{2}+(1)^{2}\right)^{1 / 2}$

$=(0+0+16+0+0,0016+0+0,25+144+$ $0,0049+0,624+0,0169+0+0,01+676+$ $1)^{1 / 2}$

$=(837,8976)^{1 / 2}$

$=28,95$

(dan seterusnya sampai $d(1,71)$ ). 


\section{Tabel 5. Data Training}

\begin{tabular}{|c|c|c|c|c|c|c|c|c|c|c|c|c|c|c|c|c|c|}
\hline \multirow{2}{*}{ No. Lab } & \multirow{2}{*}{ Lokasi } & \multicolumn{5}{|c|}{ Parameter Fisika } & \multicolumn{10}{|c|}{ Parameter Kimia } & \multirow{2}{*}{ Keterangan } \\
\hline & & Bau & Rasa & Suhu & Warna & Kekeruhar & Sisa Clor & $\mathrm{pH}$ & kesadahan & $\mathrm{Fe}$ & Mn & $\mathrm{NH}_{4}^{+}$ & $\mathrm{NO}_{2}^{-}$ & $\mathrm{KMnO}_{4}$ & $\mathrm{Cl}$ & $\mathrm{SO}_{4}{ }^{2-}$ & \\
\hline 190 & Manahan 1 & 1 & 1 & 30 & 0 & 0,41 & 0 & 7,3 & 204 & 0,42 & 0,11 & 0,84 & 0,001 & 0,32 & 50 & 11,5 & TMS \\
\hline 191 & Manahan 2 & 1 & 1 & 30 & 0 & 0 & 0 & 7,3 & 146 & 0,03 & 0,09 & 2 & 0 & 0 & 43,3 & 8,17 & MS \\
\hline 198 & Bak Manahan & 1 & 1 & 30 & 10 & 2,8 & 0 & 7,3 & 146 & 0,36 & 0,47 & 0,91 & 0,004 & 0,32 & 49 & 6,45 & MS \\
\hline 192 & Tirtonadi & 1 & 1 & 30 & 0 & 0 & 0 & 7,3 & 194 & 0,09 & 0 & 0,81 & 0 & 0 & 37 & 11,3 & TMS \\
\hline 193 & Banjarsari & 1 & 1 & 30 & 0 & 0 & 0 & 7,3 & 166 & 0,02 & 0,02 & 0,95 & 0,001 & 0 & 49 & 3,9 & MS \\
\hline 199 & Bak Banjarsari & 1 & 1 & 30,5 & 0 & 0 & 0 & 7,3 & 144 & 0 & 0,02 & 0,15 & 0,002 & 0 & 50,96 & 3,9 & MS \\
\hline 194 & Jebres 1 & 1 & 1 & 30 & 0 & 0 & 0 & 7,1 & 164 & 0,02 & 0,29 & 0,98 & 0,008 & 0,02 & 88 & 7,1 & MS \\
\hline 195 & Jebres 2 & 1 & 1 & 29 & 0 & 0 & 0 & 7,1 & 168 & 0 & 0,22 & 0,41 & 0,017 & 0 & 38,5 & 11,3 & MS \\
\hline 202 & IPA Jebres & 1 & 1 & 30 & 0 & 3,28 & 0 & 7,1 & 112 & 0,1 & 0,09 & 0,25 & 0,011 & 2,45 & 29,81 & 10,97 & MS \\
\hline 200 & Bak Jebres & 1 & 1 & 30 & 0 & 0 & 0,2 & 7,9 & 124 & 0,02 & 0,25 & 0,68 & 0,009 & 1,54 & 64,9 & 9,4 & MS \\
\hline 196 & Pedaringan & 1 & 1 & 30 & 0 & 0 & 0 & 7,1 & 112 & 0 & 0 & 0,15 & 0,002 & 0,62 & 31,25 & 11,29 & MS \\
\hline 197 & Jurug 2 & 1 & 1 & 30 & 0 & 0 & 0 & 7,8 & 90 & 0 & 0 & 0,85 & 0 & 0 & 14,74 & 6,45 & MS \\
\hline 204 & IPA Jurug & 1 & 1 & 30 & 0 & 0 & 0 & 7,1 & 114 & 0,1 & 0,01 & 0,25 & 0,011 & 2,45 & 29,8 & 11 & MS \\
\hline 205 & Mess Bengawan Solo, & 1 & 1 & 29 & 0 & 0 & 0 & 7,1 & 124 & 0,05 & 0 & 0,11 & 0 & 0 & 19,7 & 7,1 & MS \\
\hline 206 & Setyo Budiarto, Jl.AR H & 1 & 1 & 30 & 0 & 0 & 0 & 7,1 & 144 & 0,02 & 0,16 & 0,17 & 0 & 0,002 & 41,8 & 97 & MS \\
\hline 207 & Partiyem Heru, Tegal K & 1 & 1 & 29 & 0 & 0 & 0 & 7,1 & 84 & 0,02 & 0,02 & 0,21 & 0,002 & 0,62 & 28,3 & 10,7 & MS \\
\hline 208 & Siti Rochayani, Gulon & 1 & 1 & 29 & 6 & 0 & 0 & 7,3 & 84 & 0 & 0,02 & 0,13 & 0,002 & 1,23 & 32,21 & 10 & MS \\
\hline 209 & Masjid Al Muharijin, $J$ & 1 & 1 & 30 & 6 & 0 & 0 & 7,5 & 80 & 0,03 & 0,09 & 0,14 & 0 & 0,62 & 26,4 & 8,3 & MS \\
\hline 210 & Tiurlan Petoran RT 3/4 & 1 & 1 & 30 & 0 & 0 & 0 & 7,1 & 128 & 0,02 & 0,2 & 0,25 & 0,002 & 0 & 38,5 & 10,8 & MS \\
\hline 211 & Kantor PAC PDIP, Ganj & 1 & 1 & 30 & 0 & 0 & 0 & 7,1 & 124 & 0,03 & 0,11 & 0,14 & 0,006 & 1,23 & 26,4 & 9,4 & MS \\
\hline 219 & Banyuanyar & 1 & 1 & 30 & 0 & 0 & 0 & 7,3 & 134 & 0,1 & 0,36 & 0,54 & 0 & 0 & 36,41 & 4,52 & MS \\
\hline 220 & Kadipiro 1 & 2 & 1 & 30 & 0 & 0 & 0 & 7,6 & 152 & 0,05 & 0 & 0,24 & 0,02 & 0 & 11,17 & 4 & MS \\
\hline 221 & Kadipiro 2 & 1 & 1 & 30 & 0 & 0 & 0 & 7,3 & 136 & 0 & 0,29 & 0,3 & 0,024 & 0 & 25,2 & 8,2 & MS \\
\hline 222 & Kadipiro 3 & 1 & 1 & 30 & 0 & 이 & 0 & 6,9 & 148 & 이 & 0,04 & 0,12 & 0,012 & 0,62 & 26,7 & 5,8 & MS \\
\hline
\end{tabular}

Tabel 6. Data Testing

\begin{tabular}{|c|c|c|c|c|c|c|c|c|c|c|c|c|c|c|c|c|c|}
\hline \multirow{2}{*}{ No. Lab } & \multirow{2}{*}{ Lokasi } & \multicolumn{5}{|c|}{ Parameter Fisika } & \multicolumn{10}{|c|}{ Parameter Kimia } & \multirow{2}{*}{ Distance } \\
\hline & & Bau & Rasa & Suhu & Warna & Kekeruhar & Sisa Clor & $\mathrm{pH}$ & kesadahan & $\mathrm{Fe}$ & $\mathrm{Mn}$ & $\mathrm{NH}_{4}^{+}$ & $\mathrm{NO}_{2}^{-}$ & $\mathrm{KMnO}_{4}$ & $\mathrm{Cl}$ & $\mathrm{SO}_{4}{ }^{2-}$ & \\
\hline 190 & Toko Djoyo, JL. Cikarar & 1 & 1 & 26 & 0 & 0,45 & 0 & 6,8 & 192 & 0,35 & 0,9 & 0,71 & 0,001 & 0,31 & 24 & 10,5 & $?$ \\
\hline
\end{tabular}

\subsection{Pengujian}

Pengujian algoritma dengan confusion matrik digunakan untuk menghitung nilai precision, recall dan accuracy. Perhitungan kedekatan kasus lama pada data training dengan kasus baru pada data testing, diketahui dari 40 data, 33 data kelas MS diprediksi sesuai, 0 data diklasifikasikan kelas TMS, 7 data yang diprediksi kelas TMS ternyata masuk kelas MS, dan 0 data yang diprediksi MS ternyata masuk kelas TMS. Berikut tabel 5 model confusion matrix untuk algoritma KNN.

Tabel 5. Model Confusion Matriks untuk algoritma KNN

\begin{tabular}{|l|c|c|}
\hline $\begin{array}{l}\text { Nilai } \\
\text { Prediksi }\end{array}$ & \multicolumn{2}{|l|}{ Nilai Sebenarnya } \\
\cline { 2 - 3 } & MS & TMS \\
\hline $\begin{array}{l}\text { Prediksi } \\
\text { MS }\end{array}$ & 33 & 0 \\
\hline $\begin{array}{l}\text { Prediksi } \\
\text { TMS }\end{array}$ & 7 & 0 \\
\hline
\end{tabular}

Dari Tabel 5 tersebut akan dihitung nilai precision, recall dan accuracy. Berikut perhitungannya:

Precision $=\frac{T P}{T P+F P}=\frac{33}{33+7}=\frac{33}{40}=0,825=82,5 \%$
Recall $=\frac{T P}{T P+F N}=\frac{33}{33+0}=\frac{33}{33}=1=100 \%$

Accuracy $=\frac{T P+T N}{T P+F P+T N+F N}=\frac{33+0}{33+7+0+0}=$ $\frac{33}{40}=0,825=82,5 \%$

Sehingga diperoleh nilai precision $82,5 \%$, recall $100 \%$, dan accuracy $82,5 \%$.

\section{PENUTUP}

\subsection{Kesimpulan}

Berdasarkan hasil penelitian dalam menganalisa dan mengimplentasikan sistem identifikasi kualitas air dengan menggunakan algoritma K-Nearest Neighbor yang dilakukan oleh peneliti, maka dapat diambil beberapa kesimpulan, yaitu:

1. Penelitian ini berhasil menerapkan algortma K-Nearest Neighbor untuk menghitung dan memberikan hasil klasifikasi terhadap kualitas air.

2. Penelitian ini menggunakan 111 record data, 71 data digunakan sebagai data training, 40 data sebagai data testing. Dari data testing tersebut 33 data diprediksi benar dan 7 data diprediksi salah dengan perhitungan jumlah $\mathrm{K}$ sebanyak 7 . 
3. Sistem untuk identifikasi kualitas air dengan menggunakan metode KNN hasilnya akurat dengan mencapai tingkat akurasi sebesar $82,5 \%$.

\subsection{Saran}

Saran penelitian berikutnya adalah untuk menghasilkan akurasi tinggi sebaiknya digabungkan menggunakan algoritma optimasi yaitu GA (Genetik Algorithm), PSO (Particle Swam Optimzation), atau CE (CrossEntropy).

\section{DAFTAR PUSTAKA}

[1] A. St-Hilaire, T. B. M. J. Ouarda, Z. Bargaoui, A. Daigle, and L. Bilodeau, "Daily river water temperature forecast model with a k-nearest neighbour approach," Hydrol. Process., vol. 26, no. 9, pp. 1302-1310, 2012.

[2] K. Liu, Z. Li, C. Yao, J. Chen, K. Zhang, and M. Saifullah, "Coupling the knearest neighbor procedure with the Kalman filter for real-time updating of the hydraulic model in flood forecasting," Int. J. Sediment Res., vol. 31, no. 2, pp. 149-158, 2016.

[3] H.-I. Eum, S. P. Simonovic, and Y.-O. Kim, "Climate Change Impact Assessment Using K-Nearest Neighbor Weather Generator: Case Study of the Nakdong River Basin in Korea," $J$. Hydrol. Eng., vol. 15, no. 10, pp. 772785, 2010.

[4] R. I. Ndaumanu and M. R. Arief, "Analisis Prediksi Tingkat Pengunduran Diri Mahasiswa dengan Metode KNearest Neighbor," JISATI, vol. 1, no. 1, pp. 1-15, 2014.

[5] E. M. Elnahrawy, "Log-Based Chat Room Monitoring Using Text Categorization: A Comparative Study," IASTED Int. Conf. Inf. Knowl. Shar. (IKS 2002), 2002.

[6] G. Toker and Ö. Kırmemiş, "Text Categorization Using k-Nearest Neighbor Classification," Middle East Tech. Univ., 2013.

[7] Y. Liao and V. R. Vemuri, "Using Text Categorization Techniques for Intrusion Detection," Proc. 11 th USENIX Secur. Symp., 2002.

[8] F. Bajramovic, F. Mattern, N. Butko, and J. Denzler, "A comparison of nearest neighbor search algorithms for generic object recognition," Adv. Concepts Intell. Vis. Syst., pp. 1186-1197, 2006.
[9] A. . Rosa and A. Shalahuddin, Modul Pembelajaran Perangkat Lunak (Terstruktur dan Berorientasi Objek). Bandung: Modula, 2011.

[10] T. Cover and P. Hart, "Nearest neighbor pattern classification," IEEE Trans. Inf. Theory, vol. 13, no. 1, pp. 21-27, Jan. 1967.

[11] M. Bramer, Principles of Data Mining, no. January 2007. London: Springer London, 2007.

[12] K. Michelin, P. Jian, and H. Jiawei, "Data Mining: Concepts and Techniques," vol. 278, pp. 6093-6100, 2003. 